\title{
Socioeconomic position and the impact of increasing availability of lower energy meals vs. menu energy labelling on food choice: two randomized controlled trials in a virtual fast-food restaurant
}

\author{
Lucile Marty*, Andrew Jones and Eric Robinson * (1)
}

\begin{abstract}
Background: Food consumed outside of the home is often high in energy and population level interventions that reduce energy intake of people from both lower and higher socioeconomic position (SEP) are needed. There is a lack of evidence on the effectiveness and SEP equity of structural-based (e.g. increasing availability of lower energy options) and information provision (e.g. menu energy labelling) interventions on food choice.
\end{abstract}

Methods: Across two online experiments, participants of lower and higher SEP made meal choices in a novel virtual fast-food restaurant. To be eligible to take part, participants were required to be UK residents, aged 18 or above, fluent in English, have access to a computer with an internet connection and have no dietary restrictions. Participants were randomized to one of four conditions in a $2 \times 2$ between-subjects design: menu energy labelling present vs. absent and increased availability of lower energy options (75\% of menu options lower energy) vs. baseline availability (25\% of menu options lower energy). Participants also completed measures of executive function and food choice motives.

Results: The analysis of pooled data from both studies $(n=1743)$ showed that increasing the availability of lower energy options resulted in participants ordering meals with significantly less energy on average $(-71 \mathrm{kcal}$, $p<0.001$, partial $\left.\eta^{2}=0.024\right)$ and this effect was observed irrespective of participant SEP. Menu labelling had no significant effect on energy ordered $\left(-18 \mathrm{kcal}, p=0.116\right.$, partial $\left.\eta^{2}=0.001\right)$ in participants from both higher and lower SEP. Furthermore, we found no evidence that executive function or food choice motives moderated the effect of increasing lower energy menu options or energy labelling on total energy ordered.

Conclusions: In a virtual fast-food environment, energy labelling was ineffective in reducing total energy ordered for both higher and lower SEP participants. Increasing the availability of lower energy options had an equitable effect, reducing total energy ordered in participants from higher and lower SEP.

Trial registration: Study protocols and analysis plans were pre-registered on the Open Science Framework (https://osf.io/ajcr6/).

Keywords: Food choice, Energy labelling, Availability, Socioeconomic position, Executive function

\footnotetext{
* Correspondence: lucile.marty@liv.ac.uk; eric.robinson@liv.ac.uk

Department of Psychological Sciences, University of Liverpool, Eleanor

Rathbone Building, Bedford Street South, Liverpool L69 7ZA, UK
}

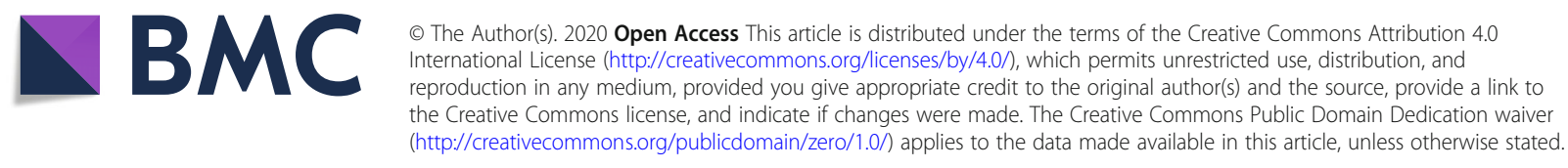




\section{Background}

Increases in population level energy intake have been identified as a key contributor to the development and maintenance of the worldwide overweight and obesity problem [13]. Although a number of factors explain why large numbers of people are consuming more energy than is optimal for health, eating out of the home $(\mathrm{OOH})$ may play an important role. In the UK, more than one quarter $(27 \%)$ of adults and one fifth (19\%) of children eat meals out once per week or more [4]. The frequency by which people eat out of the home is associated with greater daily energy intake and overweight/obesity [5-7]. This relationship may be explained by the excessive energy content of the meals in both full service and fast- food restaurants [8]. Although full service restaurants offer significantly more excessively calorific main meals compared with fast-food restaurants, fast-food consumption has been linked to higher caloric intake and greater risk for obesity $[9,10]$. In addition, people of lower socioeconomic position (SEP) might be particularly at risk because deprived areas have an increased density of fast-food outlets in the UK [11]. In the context of the overweight and obesity crisis and social inequalities in diet and health, these findings underline the need to identify effective interventions that can reduce the amount of energy (kcal) ordered and consumed in the $\mathrm{OOH}$ food sector and specifically in fast-food settings [12-14].

A commonly used intervention approach involves providing the general public with nutritional information about food in order to motivate healthier food choices ('information provision interventions'). An example of information provision is energy labelling on restaurant menus; a public health policy now implemented federally in the USA [15] and regionally in Ontario, Canada [16] and in New South Wales, Australia [17]. Although energy labelling may have a positive impact on diet through a variety of channels (e.g., reformulation of menus), encouraging customers to choose healthier meals is one of its central purposes [18]. The best available evidence on the effect that energy labelling has on meal choices in the $\mathrm{OOH}$ food sector showed a small reduction of energy purchased per meal (-7.8\%, 95\% CI: $13.1 \%$ to $-2.5 \%$ ) [19]. A different intervention approach is to change the structural properties of the food environment in which individuals make food choices ('structural-based interventions'). In the context of eating out, this could involve reducing meal portion sizes [20] or increasing the proportion of meals on restaurant menus that are lower in energy content. To date, relatively few studies have investigated the impact of altering the availability of food products on energy selected, but a recent systematic review showed a substantial reduction in mean energy selected (-35.6\%, 95\% CI: $-59.9 \%$ to $-11.7 \%$ ) [21]. A key difference between information provision and structural-based interventions is the level of individual agency required [22]. Because information provision interventions require conscious motivation and effort on the part of the individual, whereas structural-based interventions do not, it has been argued that structural-based interventions are likely to be more effective than information provision interventions [23]. However, there have been few direct comparisons of the effectiveness of information provision vs. structural-based interventions on food choice, particularly in the context of the $\mathrm{OOH}$ food sector. In the present studies, we directly compare the effect of an information provision (energy labelling) vs. a structural-based intervention (increasing availability of lower energy options) on simulated food choice.

Information provision interventions require engagement of a set of cognitive abilities called 'executive functioning' [24]; individuals need to attend to information, hold that information in mind and then consciously act on that information. In addition, for provision of nutrition information to impact on behaviour, individuals also presumably need to be motivated by health when making food choices $[25,26]$. Because lower education levels - a measure of socioeconomic position (SEP) - have been shown to be associated with reduced executive functioning $[27,28]$ and being less motivated by health when making food choices $[29,30]$, it has been argued that information provision interventions may be less effective in lower SEP population than in higher SEP [22, 31]. Conversely, because structural-based interventions do not rely on cognitive abilities or motivation, they may be more equitable and benefit all, irrespective of SEP [32]. Yet, there has been limited testing of the equity of population level interventions to improve nutritional quality of diet. For example, recent reviews have noted that it is unclear whether the effectiveness of menu energy labelling and the impact of altering the availability of healthy vs. less healthy food options differ based on SEP [19, 21, 33].

In the present studies, we made use of an online virtual fast-food environment to study the impact of an information provision and a structural-based intervention on hypothetical food ordering. Online virtual environments allow for recruitment of large and diverse samples to examine simulated food choice under tightly controlled experimental conditions. Online environments have been used to study the effect of a range of intervention types in the context of supermarket shopping behaviour [34, 35], but here we made use of a newly developed online virtual fast-food restaurant to examine simulated food choice. We conducted two studies using the same basic methodology; the second study was planned to address any methodological concerns arising from the first study and to examine replicability of findings. The main aim of the present studies was to compare the effect of energy labelling vs. increased availability of lower energy options on food choice in lower and higher SEP individuals. We also aimed to explore whether SEP differences in executive 
functioning or food choice motives may explain why these interventions may be more effective for some people than others (e.g. higher vs. lower SEP). We hypothesised that increasing the availability of lower energy options would have a significant effect on total energy ordered, and this effect would be observed irrespective of participant SEP [21]. In line with recent evidence, we hypothesised that menu energy labelling may have a modest effect on energy ordered [19] and this effect would be primarily observed among higher SEP participants. We also hypothesized that if SEP moderated the effect of energy labelling on energy ordered, it may be explained by higher SEP participants having better executive functioning and/or being more motivated by health when making food choices.

\section{Methods \\ Data collection}

Two randomized, controlled, pre-registered online experiments were conducted using the same design. Participants were recruited through the platform Prolific Academic between May and August 2019. Participants were eligible to participate if they were UK residents, aged of 18 or above, fluent in English, had access to a computer with an internet connection and had no dietary restrictions. Participants from Study 1 were ineligible to participate in Study 2. In addition, any participants who failed a quality control question (i.e., an attention check) were screened out of the study and their data was not analysed (see Additional file 1: Section 1). We intended to recruit a sample stratified by gender (approx. 50/50), highest educational qualification (approx. 60\% Alevel or below, $40 \%$ above A-level) and student status (approx. 3.5\% of students, in Study 2) to be broadly representative of the adult population in England [36, 37]. Eligible participants who completed the study received monetary compensation in return for their participation. The two experiments were approved by the Health and Life Sciences Research Ethics Committee at the University of Liverpool (reference: 4612). Informed consent was obtained from all the participants.

\section{Study design}

In a $2 \times 2$ between-subjects design, participants from Study 1 and Study 2 were randomly allocated to one of the following conditions: 'baseline availability' and 'no energy labelling' $(\mathrm{C})$, 'baseline availability' and 'energy labelling' (CL), 'increased availability of lower energy options' and 'no energy labelling' (A), 'increased availability of lower energy options' and 'energy labelling' (AL). Randomisation with 1:1:1:1 allocation was performed using the 'Random class' Microsoft algorithm [38].

\section{Measures of SEP \\ Education level}

Our primary measure of SEP was education level because it most closely captures the opportunity to develop knowledge and skills that may affect executive functioning and make a person more receptive to health information [39] and higher education level is associated with use of nutrition information when eating out [40]. We collected two similar, but distinct measures of education level; highest educational qualification and total years in higher education. Highest educational qualification was measured using the question "What is your highest educational qualification?" See Additional file 1: Section 2 for full response options. A level or below qualifications (highschool completion or below equivalent for US) were categorised as 'lower education level' whereas qualifications above A level (above high school equivalent for US) were categorised as 'higher education level', as in Best \& Papies, 2019 [41]. Years in higher education was measured using the question "After leaving school (i.e. at 16 years old), how many further years of higher education (i.e. a formal course) did you study for?" To account for both the level of qualification achieved and time spent in education, we calculated a continuous composite score ('level of education') of the z-scores for highest educational level and years in higher education.

\section{Other SEP measures}

Participants were asked to report the annual after tax income of their household including all earners to the nearest £1000. Equivalised household income [42] was calculated by dividing the after tax household income by the sum of the equivalence value of all the household members (first adult $=1$, additional adult or child aged 14 and over $=0.5$, child aged $0-13=0.3$ ). To measure perceived SEP participants rated where they think they stood in society from 1 (people who have the least money, least education and the worst jobs or no job) to 10 (people who have the most money, most education and the best jobs) using the MacArthur scale of subjective social status (SSS) [43].

\section{Additional demographic measures}

Age, gender, ethnic group, student status, height, weight, dieting status and fast-food consumption frequency were recorded. Self-reported body mass index (BMI) was calculated in $\mathrm{kg} / \mathrm{m}^{2}$.

\section{Virtual fast food restaurant ordering task Virtual fast-food restaurant}

The virtual fast-food restaurant was designed using Unity [44] and modelled on a popular fast-food chain in the UK (Fig. 1a). The participants clicked on a door to enter the restaurant and navigated around the interior of the restaurant using mouse clicks. The 

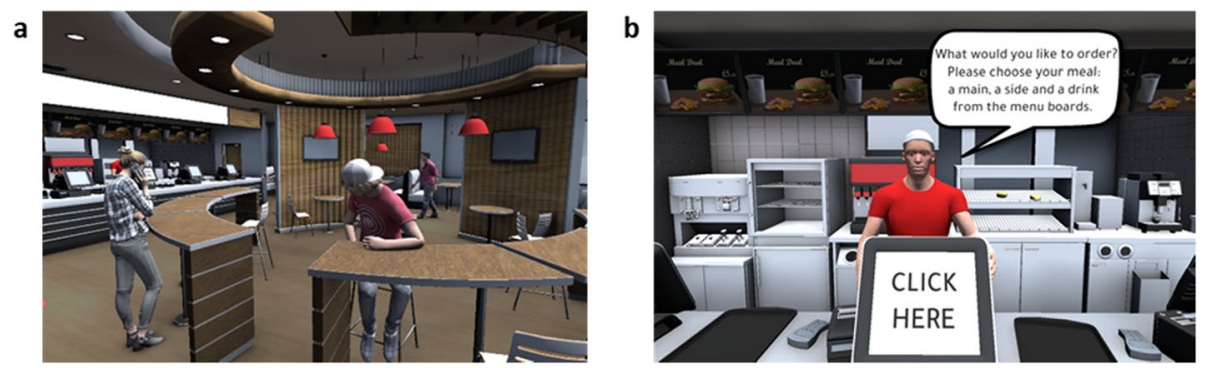

Fig. 1 Virtual fast-food restaurant developed on Unity Software. a Inside of the virtual fast food restaurant. b Virtual fast food restaurant checkout

interior included other diners and an ambient background noise of a fast-food restaurant. Once at the counter, the participants were asked by the cashier what they would like to order and clicked on menu boards to make their choice (Fig. 1b).

\section{Menu boards}

The menu boards included a picture and a name for each food item, based on 2019 menu options of a popular fast-food chain in the UK. In addition, the more detailed description of each food item appeared on the screen when the user moved the cursor over the food item. The number of food items on the menu boards (Study 1: 8 mains, 4 sides and 4 drinks; Study 2: 12 mains, 7 sides, 7 drinks) was chosen to be representative of the number of options advertised on in-store menu boards. The energy content of food and drink items was taken from the website of the fast-food chain. As there is no widely accepted definition of higher vs. lower energy for fast-food products, for the purpose of the present study food items were categorised as 'lower energy' (LE) vs. 'higher energy' (HE) based on the distribution of energy content of products being sold by the fast-food chain: LE mains $\leq 400 \mathrm{kcal}$, HE mains $\geq 500$ $\mathrm{kcal}$, LE sides $\leq 100 \mathrm{kcal}$, HE sides $\geq 200 \mathrm{kcal}$, LE drinks $\leq 10 \mathrm{kcal}$, HE drinks $\geq 40 \mathrm{kcal}$.

In the 'baseline availability' conditions ( $C$ and $C L$ ), the proportion of LE vs. HE meal options was similar to the proportion of lower vs. higher energy options in UK fast-food chains i.e. $25 \% \mathrm{LE}$ vs. $75 \% \mathrm{HE}$ in each category (mains, sides, drinks) [8]. In the 'increased availability of lower energy options' conditions (A and AL) the proportion of LE and HE food items was reversed, i.e. 75\% LE vs. $25 \%$ HE. The number of food items in each category and the food items with the highest and the lowest energy content in each category were the same across availability conditions. In the 'energy labelling' conditions ( $\mathrm{L}$ and $\mathrm{AL}$ ) energy in kcal was added on the menu boards for each item and reference information on kcal requirements was clearly displayed at the bottom of the menu: "On average women need 2,000 kcal per day and men need 2,500 kcal per day" [45]. In the "no energy labelling' conditions ( $\mathrm{C}$ and $\mathrm{A}$ ) no kcal information was included. To control for price across conditions, a fixed meal price based on an average price of a meal in the fast-food chain $(£ 5.09)$ for all meal combinations was presented. Images of the menu boards for mains are presented in Additional file 1: Section 3 - Figure S1 \& Figure S2 and menu items for each condition are described in Additional file 1: Section 3 - Table S1 \& Table S2.

\section{Primary outcome: total energy ordered}

Participants were asked to choose a main, a side and a drink by clicking on the food item they wanted to order from each menu board. The primary outcome was the total energy ordered from the virtual fast-food restaurant in kcal (including selected main, side and drink).

\section{Health motives}

To assess participants' health motives in their food choices, we used the single-item Food Choice Questionnaire [46] that includes 11 items about food choice motives. Of relevance to the present study, participants rated the following statements "It is important to me that the food I eat on a typical day: 1 / is healthy (healthiness motivation); 2 / helps me control my weight (weight control motivation)" on a scale from 1 (Not at all important) and 7 (Very important).

\section{Executive functioning Inhibition}

Inhibition is the ability to suppress impulsive or automatic responses (e.g., not choosing unhealthy foods). A Stroop task was used to measure inhibition because performance on this task has been previously related to poverty and excess energy intake [47, 48]. We implemented the classic Stroop task with keyboard input on Inquisit software [49]. Participants saw colour words written in colour and were asked to indicate the colour of the word by key press as fast as they could without making too many errors. The task included congruent trials where colour word and the colour it was presented in were the same, incongruent trials where colour word and the colour it was presented in were not the same, 
and control trials with coloured rectangles. The task included four colours (red, green, blue, black), three colour-stimuli congruency conditions, and 7 repetitions for a total of 84 trials randomly sampled. We calculated the median reaction times (RTs) for correct responses in incongruent and congruent trials [50, 51]. The Stroop interference effect was calculated as the difference between the median RTs of the incongruent trials and the congruent trials [incongruent RT - congruent RT] for correct trials only. A larger interference score is indicative of poorer inhibition. We also calculated the proportion of correct responses in incongruent trials because this outcome has been previously linked to the frequency of fatty food consumption [52].

\section{Working memory}

Working memory is the ability to monitor the relevance of incoming stimuli and update information in memory as required and is implied in goal-shielding (e.g., stick to healthy eating goals). We implemented a backwards digit-span task on Inquisit software [53] because this task has been previously used to investigate executive functioning performance in individuals with excess energy intake [47]. This task required the participants to repeat series of digits of increasing length in reversed order. If participants made a correct response the subsequent trial moved up a level (addition of a digit), if the participants made an incorrect response the subsequent trial moved down a level (removal of a digit). The first trial was a sequence of two visual digits and the task consisted of 14 trials. We calculated the two-error maximum length as the last digit-span a participant got correct before making two consecutive errors and the maximum length i.e., the maximal backward digit span that a participant recalled correctly during all 14 trials.

\section{Self-control}

The Brief Self-Control Scale (BSCS) was included as a distinct, but conceptually related measure of executive function, as it requires participants to rate their ability to exert control over their behaviour $(\alpha=0.85)$ [54].

\section{Fast-food environment questionnaire}

Participants were asked what they believed the aims of the study were (open-text). Participants who mentioned the influence of energy labelling or increased availability of lower energy options on food choices were coded as aim guessers by two independent researchers and discrepancies were resolved by a third researcher. Participants next completed seven questionnaire items to assess the fidelity of the virtual environment, whether the order they made constituted a sufficient amount of food, and whether they were influenced by the energy content of food when choosing. See Additional file 1: Section 4 for a detailed description.

\section{Procedure}

Participants were informed that the study examined food choices at fast-food restaurants. They first answered series of demographic questions including measures of SEP. Participants then completed the virtual fast-food restaurant ordering task. Participants were asked to imagine they were visiting a fast food restaurant for a main meal and to choose their meal from the menu boards, including a main item, a side and a drink. Complete instruction are available in Additional file 1: Section 3. While they were selecting the food items they would like to order, participants were able to navigate between the mains, sides and drinks menu boards and could change selected options before finalising their order. After completing the ordering task, participants next they completed the measures of food choices motivations, self-control, executive functioning and the fast-food environment questionnaire. Participants were then debriefed and paid.

\section{Statistical analyses}

We followed pre-registered analysis protocols (https://osf. io/ajcr6/). The primary analysis for Study 1 and Study 2 was an ANCOVA testing the effect of energy labelling (absent vs. present), availability (baseline vs. increased availability of lower energy options), level of education (continuous variable) and labelling*level of education and availability*level of education interactions on total energy ordered. Analyses were also performed on pooled data from Study 1 and Study 2 to examine the effect of the interventions and of level of education (continuous variable - ANCOVA) or highest educational level (binary, between subjects - ANOVA) on total energy ordered. We also tested whether any participant individual differences (executive functioning, self-control, health motives, fast-food consumption frequency) moderated the effects of availability or energy labelling on total energy ordered. ${ }^{1}$ Data from participants who did not complete the study were not included in primary analyses. ${ }^{2}$ For Study 1 and Study 2, sensitivity analyses were performed by replicating the main analyses $1 /$ after excluding aim guessers, 2/ substituting the composite variable 'level of education' for 'years in higher education' as a continuous variable, and 3/ substituting 'level of education' by 'highest educational level' as a

\footnotetext{
${ }^{1}$ As detailed in the results section, we did not find any interaction between SEP and labelling. Consequently the moderated mediation analysis that was planned to investigate the potential mediators of the differential effect of labelling in lower vs. higher SEP participants was not performed (see pre-registered analysis plan: https://osf.io/ajcr6/).

${ }^{2}$ Results remained the same when including available data from participants who dropped out. See Additional file - Section 6 - Tables S6 and S7.
} 
binary variable split into lower vs. higher education level. As secondary analyses for Study 1 and Study 2, we tested whether the effects of the interventions were moderated by alternative measures of SEP (equivalised income, SSS), or fast-food consumption frequency.

All statistical analyses described above were performed using SAS version 9.3 (SAS Institute, Inc., 2012 SAS $^{\circ}$ 9.3. Cary, NC). Statistical tests level of significance was set at $p<0.05$ for main and sensitivity analyses, and $p<0.01$ in secondary analyses to account for multiple testing. To further examine overall evidence, Bayesian analyses were also performed on pooled data as an alternative statistical approach (JASP Version 0.9.2). As opposed to frequentist analyses that can only test whether a null hypothesis can be rejected or not, Bayes factors can determine whether a null hypothesis is supported by the data [55].

\section{Sample size}

A recent meta-analysis showed a statistically significant $7 \%$ reduction in energy purchased at restaurants when menus were energy labelled [19]. As previous studies on the effect of an increased availability of lower-energy options on food selection have produced similar or larger effects than kcal labelling [21, 56, 57], we powered the study to be able to detect $7 \%$ reductions in energy purchased by intervention conditions. Based on the average energy content of menu item combinations we conservatively estimated a $30 \% \mathrm{SD}$ (of total energy ordered). We required a sample size of 788 participants for each study (197 per condition) to detect a significant main effect of energy labelling and/or availability or significant interaction effects with SEP, $80 \%$ power at $\alpha=$ 0.05 (GPower 3.1).

\section{Results \\ Participants}

Across both studies, 2650 participants started the study and data from 1743 who completed the studies were analysed (Fig. 2). Participants' characteristics are presented Table 1.

\section{Effect of the interventions and level of education on total energy ordered}

On average, the participants selected $881 \pm 217 \mathrm{kcal}$ (mean \pm SD) in Study 1 and 909 $\pm 236 \mathrm{kcal}$ (mean \pm SD) in Study 2 . Table 2 reports total energy ordered in each condition.

Study 1 showed a significant effect of availability but no significant effect of labelling and level of education. There were also no significant interactions (Table 3). Study 2 produced the same results (Table 3). Results were unchanged in sensitivity analyses and secondary analyses. See Additional file 1: Section 6 - Table S6.
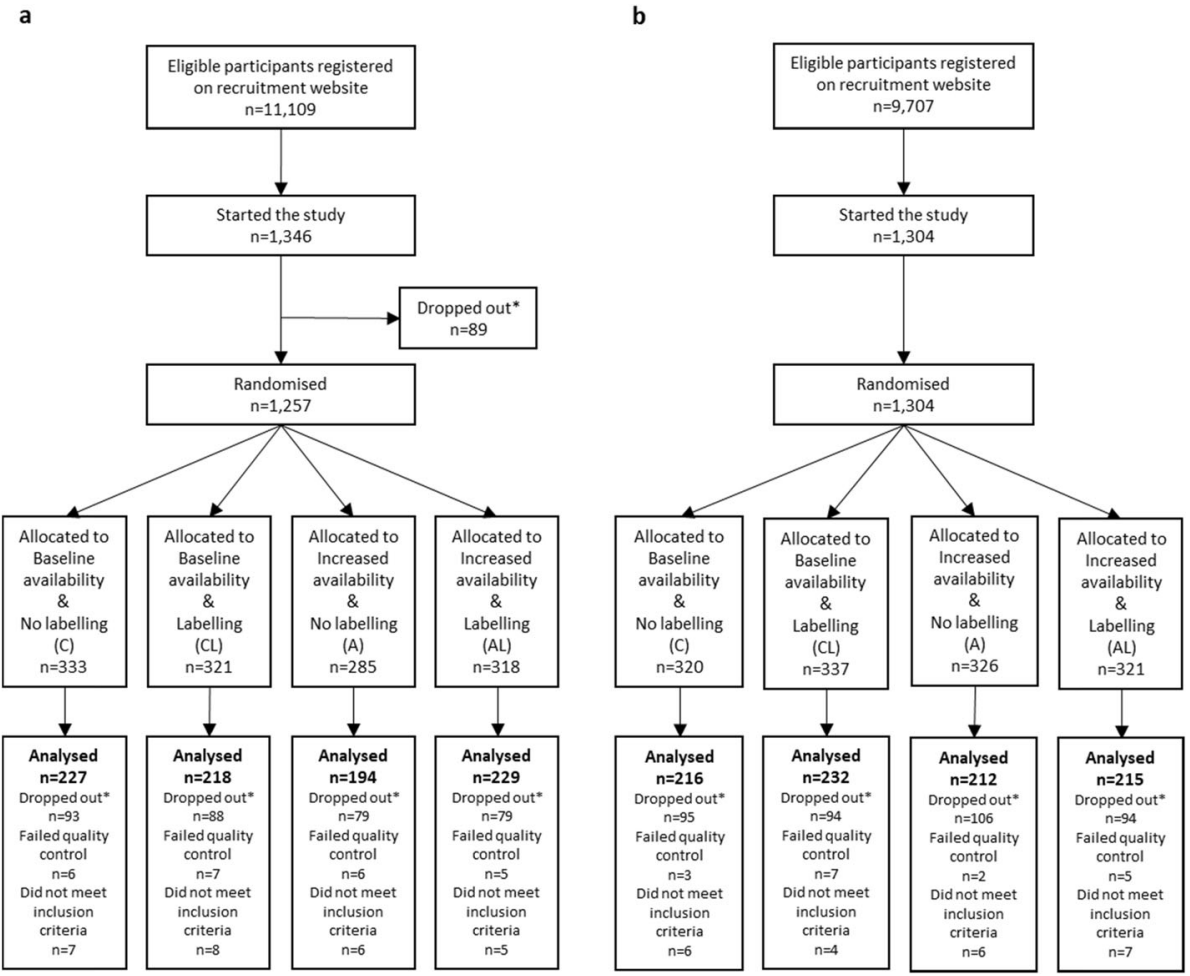

Fig. 2 Flow charts. a Study 1. b Study 2. Legend: *Dropouts were primarily due to problems with software compatibility 
Table 1 Participants' characteristics

\begin{tabular}{|c|c|c|}
\hline & $\begin{array}{l}\text { Study } 1^{\mathrm{a}} \\
(n=868)\end{array}$ & $\begin{array}{l}\text { Study } 2^{b} \\
(n=875)\end{array}$ \\
\hline Age, years, mean (SD) & $35.5(13.4)$ & $36.1(12.0)$ \\
\hline Gender, female, n (\%) & $419(48.27)$ & $463(52.91)$ \\
\hline \multicolumn{3}{|l|}{ Ethnicity, n (\%) } \\
\hline White & 789 (90.90) & $801(91.54)$ \\
\hline BMl, kg/m2, mean (SD) & $26.5(5.78)$ & $27.1(5.98)$ \\
\hline Missing, implausible, $n(\%)$ & $16(1.84)$ & $16(1.83)$ \\
\hline \multicolumn{3}{|l|}{ Highest educational level, n (\%) } \\
\hline No qualification & $17(1.96)$ & $15(1.71)$ \\
\hline 1-3 GCSES & $62(7.14)$ & $52(5.94)$ \\
\hline $4+$ GCSES & $144(16.59)$ & $119(13.60)$ \\
\hline A level & $243(28.00)$ & $286(32.69)$ \\
\hline Higher education or Bachelor's degree & $311(35.83)$ & $330(37.72)$ \\
\hline Post-Graduate degree & $91(10.48)$ & $73(8.34)$ \\
\hline Years of higher education, mean (SD) & $3.17(2.63)$ & $3.16(2.52)$ \\
\hline Equivalised income, $£$, mean (SD) & $19,652(26561)$ & 20,296 (15139) \\
\hline $\begin{array}{l}\text { Subjective socioeconomic status, } \\
\text { mean (SD) }\end{array}$ & $4.99(1.62)$ & $4.95(1.53)$ \\
\hline Student, yes, n (\%) & $217(25.00)$ & $32(3.66)$ \\
\hline \multicolumn{3}{|l|}{ Fast-food consumption frequency, n (\%) } \\
\hline Less than once per month & $259(29.84)$ & $247(28.23)$ \\
\hline 1-3 times per month & $436(50.23)$ & $456(52.46)$ \\
\hline 1 time per week or more & $173(19.93)$ & $169(19.31)$ \\
\hline Dieting status, yes, n (\%) & 119 (13.71) & $121(13.83)$ \\
\hline
\end{tabular}

To evaluate the overall body of evidence from both studies, analytic data from studies 1 and 2 were combined $(n=1743)$ and statistical analyses were run on pooled data adjusting for the origin of each participant's data (study: 1 vs. 2 included as an independent variable). The combined dataset increased the power of our main analysis from 0.80 to 0.99 (GPower 3.1). In line with the results of the individual studies, there was a significant effect of availability, whereby increasing the availability of lower energy options resulted in 71 fewer kcal ordered $\left(p<0.001\right.$, partial $\left.\eta^{2}=0.0244\right)$.
Eighteen fewer kcals were ordered in the presence vs. absence of energy labelling, but this not was significant $\left(p=0.116\right.$, partial $\left.\eta^{2}=0.0014\right)$. Education level did not significantly interact with either intervention (Table 3 \& Fig. 3). Results were unchanged when substituting level of education (continuous) with highest educational level (binary). See Additional file 1: Section 7 - Table S8. Bayes factors were computed to compare the likelihood of total energy pooled data under several models (see Additional file 1: Section 7 - Table S9). Bayes factors analysis confirmed the results obtained with frequentist statistical methods: only a model including availability as a predictor of total energy ordered was more likely than a null model $\left(\mathrm{BF}_{10}=8.329 \mathrm{e}+7\right)$.

We also tested whether any participant individual differences (executive functioning, self-control, health motives, fast-food consumption frequency) moderated the effects of availability or energy labelling using pooled data and found no evidence in support of this. See Additional file 1: Section 7 - Table S10. For completeness and to aid further research, the relationships between SEP, executive function (and the reliability of these measures), health motives and energy ordered using pooled data are reported in Additional file 1: Section 7 - Table S11 \& Table S12.

\section{Fast-food environment questionnaire}

In Study 1 and Study 2, participants questionnaire responses did not differ based on experimental condition, indicated that overall the virtual fast-food environment was representative of a real-world fast-food restaurant and participants were satisfied with their meal choices. In Study 1, a third of participants (31\%) disagreed that the range of food and drink products in the virtual fastfood restaurant items was acceptable. After increasing the range of food times in Study 2, the majority of participants $(83 \%)$ believed the range of food and drink options was acceptable. See Additional file 1: Section 4Table S3. In addition, participants tended to report that their choices were not influenced by how many calories they thought were in menu options and this did not differ between experimental conditions.

Table 2 Total energy ordered by experimental condition

\begin{tabular}{|c|c|c|c|c|c|c|}
\hline & \multicolumn{3}{|c|}{ Study 1} & \multicolumn{3}{|c|}{ Study 2} \\
\hline & $n$ & Mean & SD & $\mathrm{n}$ & Mean & SD \\
\hline Baseline availability \& No labelling (C) & 227 & 927 & 177 & 216 & 961 & 210 \\
\hline Baseline availability \& Labelling (CL) & 218 & 911 & 192 & 232 & 921 & 206 \\
\hline Increased availability \& No labelling (A) & 194 & 843 & 239 & 212 & 879 & 258 \\
\hline Increased availability \& Labelling (AL) & 229 & 839 & 243 & 215 & 874 & 257 \\
\hline
\end{tabular}


Table 3 ANCOVA models, dependant variable: total energy ordered

\begin{tabular}{llll}
\hline Model & $F$ & $p$ & partial $\eta^{2}$ \\
\hline Study 1 $(n=868)$ & & & \\
availability & 28.55 & $<0.001$ & 0.0321 \\
labelling & 0.47 & 0.494 & 0.0005 \\
level of education & 0.69 & 0.406 & 0.0008 \\
availability*level of education & 2.34 & 0.127 & 0.0027 \\
labelling*level of education & 0.52 & 0.471 & 0.0006 \\
Study 2 ( $n=875$ ) & & & \\
availability & 16.29 & $<0.001$ & 0.0184 \\
labelling & 2.01 & 0.157 & 0.0023 \\
level of education & 2.92 & 0.088 & 0.0033 \\
availability*level of education & 0.02 & 0.875 & $<0.0001$ \\
labelling*level of education & 0.17 & 0.680 & 0.0002 \\
Pooled data ( $n=1743$ ) & & & \\
availability & 43.35 & $<0.001$ & 0.0244 \\
labelling & 2.47 & 0.116 & 0.0014 \\
level of education & 0.31 & 0.575 & 0.0002 \\
availability*level of education & 1.27 & 0.260 & 0.0007 \\
labelling*level of education & 0.05 & 0.816 & $<0.0001$ \\
study & 6.95 & 0.009 & 0.0040 \\
\hline
\end{tabular}

\section{Discussion}

Across two studies we examined the effect of increasing the availability of lower energy menu options and providing menu energy labelling on total energy ordered by participants of higher and lower SEP in a virtual fastfood restaurant. Increasing the availability of lower energy options (from 25 to $75 \%$ ) resulted in participants ordering meals with statistically significantly less energy on average (-71 kcal, $7.6 \%$ reduction). Menu energy labelling had no statistically significant effect on total energy ordered (-18 kcal, $2.0 \%$ reduction). We found no evidence that participant SEP moderated the effect of availability or energy labelling on total energy ordered, irrespective of whether SEP was based on education level, household income or subjective (participant perceived) SEP.

The effect of increasing availability of lower energy options on food choice is consistent with other studies [57, 59] and the lack of moderation by SEP is consistent with the proposition that 'structural-based' interventions to improve nutrition are likely to be equitable [32]. Based on mixed findings to date, we tentatively predicted that there would be a small effect of energy labelling on total energy ordered and that this effect would be predominantly observed among participants from higher SEP. However, there was no significant effect of menu energy labelling in either study or in a larger pooled analysis. In the pooled analysis a small non-significant reduction in energy ordered was observed, which is consistent with the conclusions of recent systematic reviews; energy labelling has no measurable impact $[60,61]$ or only a very small effect on amount of energy ordered when eating out [19]. Furthermore, we found no evidence that energy labelling was any more effective when there was an increased range of lower energy menu options (interaction between interventions). Given that there is need to consider whether policies can ameliorate SEP inequalities in obesity [62], the present findings suggest that neither increasing availability of lower energy options nor energy labelling in fast food restaurants are likely to directly achieve this aim by altering the food choices of lower vs. higher SEP populations.

We found some evidence that participants with a higher SEP tended to report being more strongly motivated by

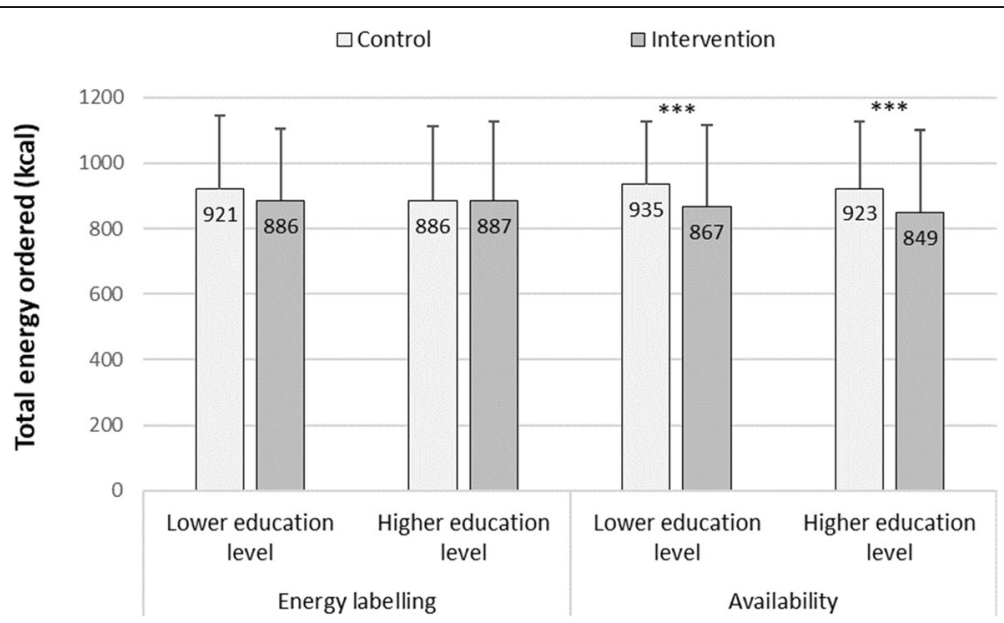

Fig. 3 Mean (+ SD) of total energy ordered for pooled data. Legend: Energy labelling control: $C$ and A conditions, energy labelling intervention: $\mathrm{CL}$ and $\mathrm{AL}$ conditions, availability control: $\mathrm{C}$ and $\mathrm{CL}$ conditions, availability intervention: $\mathrm{A}$ and $\mathrm{AL}$ conditions. Lower education level: $\mathrm{A}$ level or below, higher education level: above A-level. ${ }^{* * *} p<0.001$ least square means post-hoc tests 
weight control, health and calories when making food choices and had greater executive functioning performance than lower SEP participants (reported in Additional file 1). However, we failed to find evidence in support of the proposition that energy labelling is more effective in changing the diet of higher as opposed to lower SEP participants [22]. We also examined other potential moderators of the impact of energy labelling or availability on total energy ordered (executive functioning, selfcontrol, healthiness and weight control motivation, fastfood consumption frequency), but found no supporting evidence (reported in Additional file 1). The lack of effect of energy labelling observed may relate to the restaurant environment used. There is mixed evidence on the impact of energy labelling on purchases made in fast-food restaurants [63, 64]. Fast-food purchases may be perceived as being an indulgence or 'treat' and therefore customers do not base their choices on health. In line with this, we found that only a small minority of participants reported being influenced by the energy content of the food in labelling condition in the present studies (23\% in Study 1, $20 \%$ Study 2). In addition, the food items used in both studies were from a popular fast food chain in the UK. The effect of energy labelling on energy ordered may depend on existing knowledge about the energy content of menu items, whereby energy labelling may only impact behaviour when consumers are confronted with nutrition information that does not align with their expectations [65]. Future research is needed to explore further the effect of these interventions in different settings (e.g., fullservice restaurants) and to test whether menu options people are unaware of the energy content of are more likely to be affected by energy labelling.

Strengths of the present studies included preregistration, high statistical power and balanced recruitment of a large number of participants from higher and lower SEPs. However, the participants were recruited through a self-selected online panel which limits the generalisability of the results. Our main measure of SEP was education level. Although results were consistent irrespective of SEP measure used (education, income, perceived SEP) we did not examine all possible SEP measures (e.g. occupation), but we are not aware of a convincing hypothesis of why the effects of availability or energy labelling would be moderated by other measures of SEP. A strength of using virtual environments is that hypotheses can be tested under tightly controlled experimental conditions. The virtual fast-food restaurant used was created for the present studies and has therefore not been validated. We based the restaurant design and menu information (including meal choices, energy content, price) on a popular UK fast-food restaurant and participants reported that the food items in the virtual environment were common in fast-food restaurants, and that there were food items they would have normally ordered in the real world. We also found evidence that participants' food choices in the virtual environment were similar to what would be expected in everyday life, e.g., as shown in other research [30,66], participants tended to order less energy overall if they reported being motivated by health when making everyday food choices. Although other research has shown that food choice tasks using virtual environments are valid [67, 68], participants did not spend their own money and did not have to consume what they ordered. Moreover, the food items were from one fast food chain and generalizing results to other eating out settings should be done with caution. Thus, replicating the present findings in diverse real-world settings and measuring actual choice behaviour in fast-food restaurants is now needed.

\section{Conclusion}

In a virtual fast-food environment, energy labelling was ineffective in reducing total energy ordered for participants of both higher and lower SEP. Increasing the availability of lower energy options had an equitable effect, reducing total energy ordered in participants from higher and lower SEP.

\section{Supplementary information}

Supplementary information accompanies this paper at https://doi.org/10. 1186/s12966-020-0922-2.

Additional file 1. All additional materials and data.

\section{Abbreviations}

A: 'increased availability of lower energy options' and 'no energy labelling'; AL: 'increased availability of lower energy options' and 'energy labelling'; BMI: Body mass index; C: 'baseline availability' and 'no energy labelling'; CL: 'baseline availability' and 'energy labelling'; HE: Higher energy; LE: Lower energy; SD: Standard deviation; SEP: Socioeconomic position

\section{Acknowledgements}

The authors thank the team from the Virtual Engineering Centre, University of Liverpool who developed the virtual fast-food environment: Carlo Pinto, lain Cant and Lynn Dwyer.

\section{Authors' contributions}

All authors collaborated in designing the study protocol. LM collected study data and performed the analyses. ER and LM drafted the manuscript and AJ provided critical revisions. All authors read and approved the final manuscript.

\section{Funding}

This project has received funding from the European Research Council (ERC) under the European Union's Horizon 2020 research and innovation programme (Grant reference: PIDS, 803194).

Availability of data and materials

The datasets analysed during the current studies are available on the Open Science Framework project page https://osf.io/ajcr6/.

\section{Ethics approval and consent to participate}

Approved by the Health and Life Sciences Research Ethics Committee at the University of Liverpool (reference number: 4612). Informed consent was obtained from all the participants before they started the study. 


\section{Consent for publication}

Not applicable.

\section{Competing interests}

ER has previously been the recipient of research funding from Unilever and the American Beverage Association. However, he does not consider this to be a conflict of interest for the present research. The other authors declare that they have no competing interests.

\section{Received: 24 October 2019 Accepted: 27 January 2020}

Published online: 31 January 2020

\section{References}

1. Swinburn B, Sacks G, Ravussin E. Increased food energy supply is more than sufficient to explain the US epidemic of obesity. Am J Clin Nutr. 2009;90:1453-6.

2. Swinburn BA, Sacks G, Hall KD, McPherson K, Finegood DT, Moodie ML, et al. The global obesity pandemic: shaped by global drivers and local environments. Lancet. 2011;378:804-14.

3. Vandevijvere $\mathrm{S}$, Chow CC, Hall KD, Umali E, Swinburn BA. Increased food energy supply as a major driver of the obesity epidemic: a global analysis. Bull World Health Organ. 2015;93:446-56.

4. Adams J, Goffe L, Brown T, Lake AA, Summerbell C, White M, et al. Frequency and socio-demographic correlates of eating meals out and takeaway meals at home: cross-sectional analysis of the UK national diet and nutrition survey, waves 1-4 (2008-12). Int J Behav Nutr Phys Act. 2015;12:1-9.

5. Lachat C, Nago E, Verstraeten R, Roberfroid D, Van Camp J, Kolsteren P. Eating out of home and its association with dietary intake: a systematic review of the evidence. Obes Rev. 2012;13:329-46.

6. Nago ES, Lachat CK, Dossa RAM, Kolsteren PW. Association of out-of-Home Eating with anthropometric changes: a systematic review of prospective studies. Crit Rev Food Sci Nutr. 2014;54:1103-16.

7. Bezerra IN, Curioni C, Sichieri R. Association between eating out of home and body weight. Nutr Rev. 2012;70:65-79.

8. Robinson E, Jones A, Whitelock V, Mead BR, Haynes A. (over)eating out at major UK restaurant chains: observational study of energy content of main meals. BMJ. 2018;363:1-8.

9. Pereira MA, Kartashov Al, Ebbeling CB, Van Horn L, Slattery ML, Jacobs PDR, et al. Fast-food habits, weight gain, and insulin resistance (the CARDIA study): 15-year prospective analysis. Lancet. 2005;365:36-42.

10. Bowman SA, Vinyard BT. Fast food consumption of U.S. adults: impact on energy and nutrient intakes and overweight status. J Am Coll Nutr. 2004;23:163-8.

11. Burgoine T, Forouhi NG, Griffin SJ, Brage S, Wareham NJ, Monsivais P. Does neighborhood fast-food outlet exposure amplify inequalities in diet and obesity? A cross-sectional study. Am J Clin Nutr. 2016:103:1540-7.

12. Secretary of State for Health. Healthy Lives, Healthy People : Our strategy for public health in England. HM Gov. 2010.

13. Popkin BM. The public health implications of fast-food menu labeling. Am J Prev Med. 2012:43:569-70.

14. Hillier-Brown FC, Summerbell CD, Moore HJ, Wrieden WL, Adams J, Abraham C, et al. A description of interventions promoting healthier readyto-eat meals (to eat in, to take away, or to be delivered) sold by specific food outlets in England: a systematic mapping and evidence synthesis. BMC Public Health. 2017;17:1-17.

15. Cleveland LP, Simon D, Block JP. Compliance in 2017 with federal calorie labeling in 90 chain restaurants and 10 retail food outlets prior to required implementation. Am J Public Health. 2018;108:1099-102.

16. Government of Ontario. Healthy Menu Choices Act. 2015 p. S.O. 2015, CHAPTER 7, SCHEDULE 1.

17. NSW Government - Food Authority. kJ labelling nutrition information [Internet]. 2017 [cited 2019 Dec 17]. Available from: http://www. foodauthority.nsw.gov.au/ip/legislation/proposals-and-policy/kJ-labellingnutrition-information

18. VanEpps EM, Roberto CA, Park S, Economos CD, Bleich SN. Restaurant menu labeling policy: review of evidence and controversies. Curr Obes Rep. 2016;5:72-80.

19. Crockett RA, King SE, Marteau TM, Prevost AT, Bignardi G, Roberts NW, et al. Nutritional labelling for healthier food or non-alcoholic drink purchasing and consumption. Cochrane Database Syst Rev. 2018;2:CD009315.

20. Marteau TM, Hollands GJ, Shemilt I, Jebb SA. Downsizing: policy options to reduce portion sizes to help tackle obesity. BMJ. 2015;351:1-5.

21. Hollands GJ, Carter P, Anwer S, King SE, Jebb SA, Ogilvie D, et al. Altering the availability or proximity of food, alcohol, and tobacco products to change their selection and consumption. Cochrane Database Syst Rev. 2019:9:CD012573.

22. Adams J, Mytton $\mathrm{O}$, White $\mathrm{M}$, Monsivais $\mathrm{P}$. Why are some population interventions for diet and obesity more equitable and effective than others? The role of individual agency. PLoS Med. 2016;13:1-7.

23. Capewell S, Capewell A. An effectiveness hierarchy of preventive interventions: Neglected paradigm or self-evident truth? J Public Heal (United Kingdom). 2017;40:350-8.

24. Banish MT. Executive function: the search for an integrated account. Curr Dir Psychol Sci. 2009;18:89-94.

25. Grunert KG, Fernández-Celemín L, Wills JM, Bonsmann SSG, Nureeva L. Use and understanding of nutrition information on food labels in six European countries. J Public Heal (United Kingdom). 2010;18:261-77.

26. Drichoutis AC, Lazaridis $P$, Nayga RM. Nutrition knowledge and consumer use of nutritional food labels. Eur Rev Agric Econ. 2005;32:93-118.

27. Kao K, Nayak S, Doan SN, Tarullo AR. Relations between parent EF and child EF: the role of socioeconomic status and parenting on executive functioning in early childhood. Transl Issues Psychol Sci. 2018;4:122-37.

28. Lawson GM, Hook CJ, Farah MJ. A meta-analysis of the relationship between socioeconomic status and executive function performance among children. Dev Sci. 2018;21:1-22.

29. Pechey R, Monsivais P, Ng YL, Marteau TM. Why don't poor men eat fruit? Socioeconomic differences in motivations for fruit consumption. Appetite. 2015;84:271-9.

30. Konttinen H, Sarlio-Lähteenkonva S, Silventoinen K, Männistö S, Haukkala A. Socio-economic disparities in the consumption of vegetables, fruit and energydense foods: the role of motive priorities. Public Health Nutr. 2012;16:873-82.

31. Beauchamp A, Backholer K, Magliano D, Peeters A. The effect of obesity prevention interventions according to socioeconomic position: a systematic review. Obes Rev. 2014;15:541-54.

32. Hall PA, Marteau TM. Executive function in the context of chronic disease prevention: theory, research and practice. Prev Med (Baltim). 2014;68:44-50.

33. Sarink D, Peeters A, Freak-Poli R, Beauchamp A, Woods J, Ball K, et al. The impact of menu energy labelling across socioeconomic groups: a systematic review. Appetite. 2016;99:59-75.

34. Waterlander WE, Jiang Y, Steenhuis IHM, Ni MC. Using a $3 D$ virtual supermarket to measure food purchase behavior: a validation study. J Med Internet Res. 2015;17:e107.

35. Parsons TD, McMahan T. An initial validation of the Virtual Environment Grocery Store. J Neurosci Methods. 2017;291:13-9 Elsevier B.V.

36. HESA. Higher Education Student Statistics: UK, 2017/18 [Internet]. Stat. Bull. SB252. 2019 [cited 2019 Jun 11]. Available from: https://www.hesa.ac.uk/ news/17-01-2019/sb252-higher-education-student-statistics

37. Office for National Statistics. 2011 Census-based reweighting of Labour Force Survey estimates 2014.

38. Microsoft. Random Class [Internet]. 2019 [cited 2019 Sep 25]. Available from: https:// docs.microsoft.com/en-us/dotnet/api/system.random?view=netframework-4.8

39. Galobardes B, Shaw M, Lawlor DA, Lynch JW, Smith GD. Indicators of socioeconomic position (part 1). J Epidemiol Community Health. 2006;60:7-12.

40. Breck A, Cantor J, Martinez O, Elbel B. Who reports noticing and using calorie information posted on fast food restaurant menus? Appetite. 2014;81:30-6.

41. Best M, Papies EK. Lower socioeconomic status is associated with higher intended consumption from oversized portions of unhealthy food. Appetite. 2019:140:255-68.

42. Office for National Statistics. Chapter 3: Equivalised income. UK: Compend Fam Spend; 2015.

43. Adler NE, Epel E, Casterllazzo G, Ickovics J. Relationship of subjective and objective social status with psychological and physical health in healthy white women. Health Psychol. 2000;19:586-92.

44. (c) 2019 Unity Technologies. Unity [Internet]. 2019 [cited 2019 Oct 15]. Available from: https://unity.com/

45. Food Standards Agency. Guidance on voluntary energy (kJ/kcal) labelling for out of home businesses. 2017.

46. Onwezen MC, Reinders MJ, Verain MCD, Snoek HM. The development of a single-item food choice questionnaire. Food Qual Prefer. 2019:71:34-45.

47. Yang Y, Shields GS, Guo C, Liu Y. Executive function performance in obesity and overweight individuals: a meta-analysis and review. Neurosci Biobehav Rev. 2018;84:225-44.

48. Andani M, Sendhil M, Eldar S, Jiaying Z. Poverty Impedes Cognitive Function. Science (80- ). 2013;341:976-80.

49. Stroop JR. Studies of interference in serial verbal reactions. J Exp Psychol. 1935;18:643-62. 
50. Rousselet GA, Wilcox RR. Reaction times and other skewed distributions: problems with the mean and the median. Meta-Psychology. 2018. Available online at: https://www.biorxiv.org/content/biorxiv/early/2018/08/10/383935. full.pdf.

51. Ratcliff R. Methods for dealing with RT outliers. Psychol Bull. 1993;114:510-32.

52. Hall PA. Executive control resources and frequency of fatty food consumption: findings from an age-stratified community sample. Health Psychol. 2012;31:235-41.

53. Woods DL, Kishiyama MM, Yund EW, Herron TJ, Edwards B, Hink RF, et al. Improving digit span assessment. J Clin Exp Neuropsychol. 2011;33:101-11.

54. Tangney JP, Baumeister RF, Boone AL. High self-control predicts good better grades, and interpersonal success. J Pers. 2004;72:271-322.

55. Lee M, Wagenmakers E. Bayesian Cognitive Model: A Practical Course. Cambridge: Cambridge University Press; 2013.

56. Pechey R, Cartwright E, Pilling M, Hollands GJ, Vasiljevic M, Jebb SA, et al. Impact of increasing the proportion of healthier foods available on energy purchased in worksite cafeterias: a stepped wedge randomized controlled pilot trial. Appetite. 2019;133:286-96.

57. Van Kleef E, Otten K, Van Trijp HCM. Healthy snacks at the checkout counter: a lab and field study on the impact of shelf arrangement and assortment structure on consumer choices. BMC Public Health. 2012;12:1-10.

58. Laxy M, Teuner C, Holle R, Kurz C. The association between BMl and healthrelated quality of life in the US population: sex, age and ethnicity matters. Int J Obes. 2018;42:318-26.

59. Pechey R, Marteau TM. Availability of healthier vs less healthy food and food choice: an online experiment. BMC Public Health. 2018;18:1296.

60. Long MW, Tobias DK, Cradock AL, Batchelder H, Gortmaker SL. Systematic review and meta-analysis of the impact of restaurant menu calorie labeling. Am J Public Health. 2015;105:e11-24.

61. Cantu-Jungles TM, McCormack LA, Slaven JE, Slebodnik M, Eicher-Miller HA. A meta-analysis to determine the impact of restaurant menu labeling on calories and nutrients (Ordered or consumed) in U.S. adults. Nutrients. 2017;9:20-2.

62. Olstad DL, Teychenne M, Minaker LM, Taber DR, Raine KD, Nykiforuk CIJ, et al. Can policy ameliorate socioeconomic inequities in obesity and obesity-related behaviours? A systematic review of the impact of universal policies on adults and children. Obes Rev. 2016;17:1198-217.

63. Bleich SN, Economos CD, Spiker ML, Vercammen KA, VanEpps EM, Block JP, et al. A systematic review of calorie labeling and modified calorie labeling interventions: impact on consumer and restaurant behavior. Obesity. 2017; 25:2018-44.

64. Dumanovsky T, Huang CY, Nonas CA, Matte TD, Bassett MT, Silver LD. Changes in energy content of lunchtime purchases from fast food restaurants after introduction of calorie labelling: cross sectional customer surveys. BMJ. 2011;343:1-11.

65. Burton S, Howlett E, Tangari AH. Food for thought: how will the nutrition labeling of quick service restaurant menu items influence consumers' product evaluations, purchase intentions, and choices? J Retail. 2009;85:258-73.

66. Naughton P, McCarthy SN, McCarthy MB. The creation of a healthy eating motivation score and its association with food choice and physical activity in a cross sectional sample of Irish adults. Int J Behav Nutr Phys Act. 2015;12:1-10.

67. Sharpe KM, Staelin R, Huber J. Using extremeness aversion to fight obesity: policy implications of context dependent demand. J Consum Res. 2008;35:406-22.

68. van Herpen E, van den Broek E, van Trijp HCM, Yu T. Can a virtual supermarket bring realism into the lab? Comparing shopping behavior using virtual and pictorial store representations to behavior in a physical store. Appetite. 2016;107:196-207.

\section{Publisher's Note}

Springer Nature remains neutral with regard to jurisdictional claims in published maps and institutional affiliations.

Ready to submit your research? Choose BMC and benefit from:

- fast, convenient online submission

- thorough peer review by experienced researchers in your field

- rapid publication on acceptance

- support for research data, including large and complex data types

- gold Open Access which fosters wider collaboration and increased citations

- maximum visibility for your research: over $100 \mathrm{M}$ website views per year

At BMC, research is always in progress.

Learn more biomedcentral.com/submissions 